\title{
A Review of Electroanalytical Techniques for Determination of Anti-HIV Drugs
}

\author{
Burçin Bozal, Bengi Uslu, and Sibel A. Özkan \\ Department of Analytical Chemistry, Faculty of Pharmacy, Ankara University, Tandogan, 06100 Ankara, Turkey \\ Correspondence should be addressed to Bengi Uslu, buslu@pharmacy.ankara.edu.tr
}

Received 19 February 2011; Accepted 21 February 2011

Academic Editor: Hassan Y. Aboul-Enein

Copyright () 2011 Burçin Bozal et al. This is an open access article distributed under the Creative Commons Attribution License, which permits unrestricted use, distribution, and reproduction in any medium, provided the original work is properly cited.

\begin{abstract}
Until now after the human immunodeficiency virus (HIV) was discovered as the thentative aetiological agent of acquired immune deficiency syndrome (AIDS), exactly 25 anti-HIV compounds have been formally approved for clinical use in the treatment of AIDS. These compounds fall into six categories: nucleoside reverse transcriptase inhibitors (NRTIs: zidovudine, didanosine, zalcitabine, lamivudine, abacavir, stavudine, and emtricitabine), nucleotide reverse transcriptase inhibitors (NtRTIs: tenofovir), nonnucleoside reverse transcriptase inhibitors (NNRTIs: efavirenz, nevirapine, delavirdine, and etravirine), protease inhibitors (PIs: ritonavir, indinavir, saquinavir, nelfinavir, amprenavir, lopinavir, fosamprenavir, atazanavir, tipranavir and darunavir), fusion inhibitors (FIs: enfuvirtide), coreceptor inhibitors (CRIs: maraviroc), and integrase inhibitors (INIs: raltegravir). The present paper submitted the use of various electroanalytical techniques for the determination of anti-HIV drugs. This paper covers the time period from 1990 to 2010 including voltammetric techniques that were reported. Presented application concerns analysis of anti-HIV drugs from pharmaceutical dosage forms and biological samples.
\end{abstract}

\section{Introduction}

In these early days of anti-HIV drug research, it could hardly be foreseen that within 27 years of the virus being discovered we would now, in 2010, have at hand 25 anti-HIV compounds licensed (thus formally approved) for the treatment of AIDS according to different categories (Table 1).

(a) Nucleoside reverse transcriptase inhibitors (NRTIs): the reverse transcriptase associated with HIV is actually the target for three classes of inhibitors: NRTIs, NtRTIs, and NNRTIs. The NRTIs and NtRTIs interact with the catalytic site of the enzyme, whereas the NNRTIs interact with an allosteric site located at a short distance from catalytic site [1]. There are at present (in 2010) 7 NRTIs that have been formally approved for the treatment of HIV infections: zidovudine, didanosine, zalcitabine, lamivudine, abacavir, stavudine and emtricitabine (Table 1). All the NRTIs could be considered as $2^{\prime}, 3^{\prime}$ dideoxynucleoside analogues and act in a similar fashion. (b) Nucleotide reverse transcriptase inhibitors (NtRTIs): NtRTIs should be clearly distinguished from the NRTIs as they are nucleotide analogues, which means that they only need two phosphorylation steps to be converted to their active form. Also, they contain a phosphonate group that cannot be cleaved by esterases, which would make it more difficult to cleave off these compounds, once incorporated at the $3^{\prime}$-terminal end, compared with their regular nucleotide counterpart. At present, there is only one NtRTI that has been formally approved for the treatment of HIV infections: tenofovir (Table 1).

(c) Nonnucleoside reverse transcriptase inhibitors (NNRTIs): NNRTIs attack the same target enzyme as NRTIs. However, rather than integrating themselves into the transcribed DNA, NNRTIs attach themselves to reverse transcriptase and prevent the enzyme from converting RNA to DNA. Unlike NRTIs, which must be phosphorylated to prevent HIV from infecting the cell, NNRTIs are active in the form administered. The four NNRTIs presently available for the treatment of 
HIV infections are efavirenz, nevirapine, delavirdine, and etravirine $[1,2]$ (Table 1).

(d) Protease inhibitors (PIs): during the later stages of the HIV growth cycle, the Gag and Gag-Pol gene products are translated into polyproteins, and these become immature budding particles. Protease is responsible for cleaving these precursor molecules to produce the final structural proteins of the mature virion care. By preventing posttranslational cleavage of the Gag-Pol polyprotein, PIs prevent the processing of viral proteins into functional conformations, resulting in the production of immature, noninfectious viral particles. PIs are active against both HIV-1 and HIV-2; unlike the NRTIs, however, they do not need intracellular activation. The ten PIs currently available for the treatment of HIV infections are ritonavir, indinavir, saquinavir, nelfinavir, amprenavir, lopinavir, fosamprenavir, atazanavir, tipranavir, and darunavir [1-6].

(e) Entry inhibitors (fusion inhibitors and coreceptor inhibitors): the process of HIV-1 entry into host cell is complex; each step forms a potential target for inhibition. Viral attachment to the host cell entails binding of the viral envelope glycoprotein complex gp160 to its cellular receptor CD4. At present, there are only two entry inhibitors that have been formally approved for the treatment of HIV infections: enfuvirtide and maraviroc (Table 1) [1-6].

(f) Integrase inhibitors (INIs): although integrase has been pursued for many years as a potential target for the development of new anti-HIV compounds, the first integrase inhibitor licensed for clinical use, raltegravir, has only recently been approved. Raltegravir is a pyrimidinone analog that binds integrase, a viral enzyme essential to the replication of both HIV-1 and HIV-2. It is licensed for use in treatment-experienced adult patients infected with strains of HIV-1 resistant to multiple other agents.

In addition, new therapies are continually being sought that exploit new viral targets, have activity against resistant viral strains, have a lower incidence of adverse effects, and offer convenient dosing. New agents of existing classes are currently in advanced stages of clinical development [1-6].

The growing demand for these agents stimulates a search for new even more effective drugs, but also calls for higher level of quality control of these therapeutic substances and preparations, so that they are in the highest possible degree free from any impurities that may come from the production process, as well as from decompositions products of active or auxiliary substances. Therefore, it seems appropriate to develop new analytical methods regarding their qualitative and quantitative analysis. For this aim, different analytical methods are used for determining anti-HIV drugs. One that has been gaining more and more applications is the electroanalytical methods. Electroanalytical methods are widely used in scientific studies and in monitoring of industrial materials, pharmaceutical compounds, biological samples and the environment. The most widespread electroanalytical methods are voltammetry and polarography. These methods permit the screening and determination of a great number of organic compounds especially pharmaceutical substances with a detection limit of $\sim 10^{-7} \mathrm{M}$. The voltammetric methods used today in analytical chemistry laboratories were made possible by recent advances in instrumentation, by computerized processing of analytical data, and in particular, by innovative electrochemists. Electrochemistry involves in its broad sense a chemical phenomenon associated with charge separation at an electrode surface. As voltammetric methods continue to develop, the range of working electrode materials continues to expand, and the analyst must remain aware of what is available. Both the geometry and composition of the working electrode material must be considered since they will influence the performance of the voltammetric method. Also, the physical form of the working electrode may influence the diffusion process and the electron transfer process involved in the detection of the analyte [7-15]. The voltammetric and polarographic analysis of drugs in pharmaceutical preparations by far is the most common use of electrochemistry for analytical-pharmaceutical problems. As a rule, many of active compounds of the formulations can be readily oxidized or reduced. As has been pointed out, electrochemical techniques are well suited for the determination of drugs in various samples, that is, raw material, pharmaceutical dosage forms even those involving a complex matrix such as syrups, tablets, creams, suppositories, or ointments, or else in biological fluids. The principal advantage of the modern electroanalytical methods is that the excipients do not interfere, and generally the separation and extraction is not necessary. Thus, sample preparation usually consists of dissolving out the active substance from the pharmaceutical dosage form with a suitable solvent and performing direct analysis on an aliquot portion of this solution [16]. Electrochemical techniques are most suitable to investigate the redox properties of a new drug (like new anti-HIV agents); this can give insights into its metabolic fate. Electrochemical data are often correlated to the molecular structure and the pharmacological activity. Also, interactions of drugs with metal ions or with proteins as well as degredation processes occurring on photo- or $\mathrm{pH}$ sensitive drugs may be studied using modern electrochemical techniques $[9,16,17]$.

Anti-HIV drugs are the recent developments of drugs and there is a great need to review the analytical work reported so far in the literatures. Efforts have been made to collect the literature from 1990 up to the present. For electroanalytical determinations, CV, LSV, DPV, SWV, and polarography have been used.

\section{Electroanalytical Methods for Anti-HIV Drug Determination}

2.1. Efavirenz. EFV, (S)-6-chloro-4-(cyclopropylethynyl)-1, 4-dihydro-4-(trifluoromethyl)-2H-3,1-benzoxazin-2-one, is an HIV-1 spesific, nonnucleoside reverse transcriptase inhibitor. EFV was approved by the FDA on September 21, 1998, making it the 14th approved antiretroviral drug. It is not 


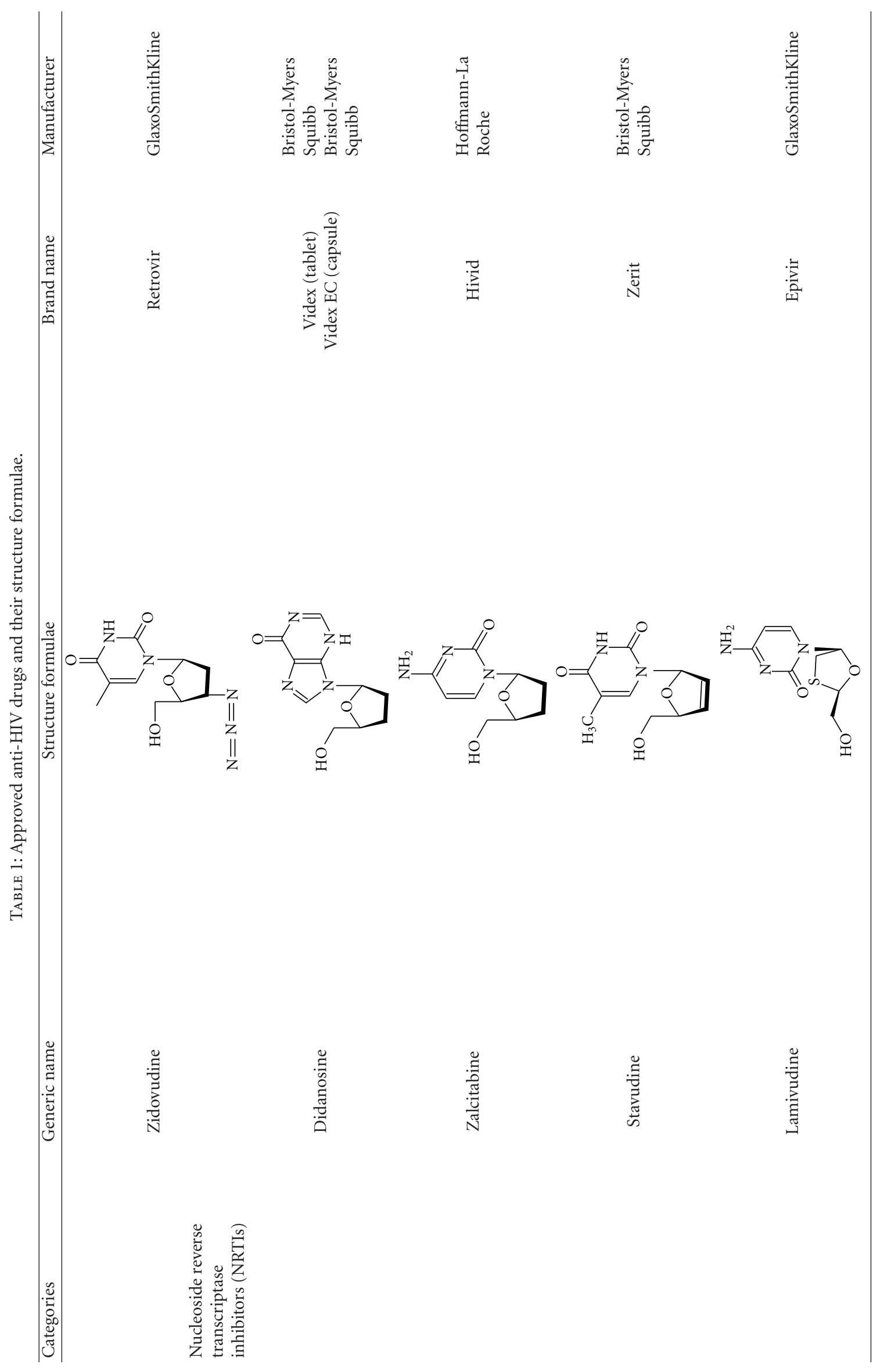




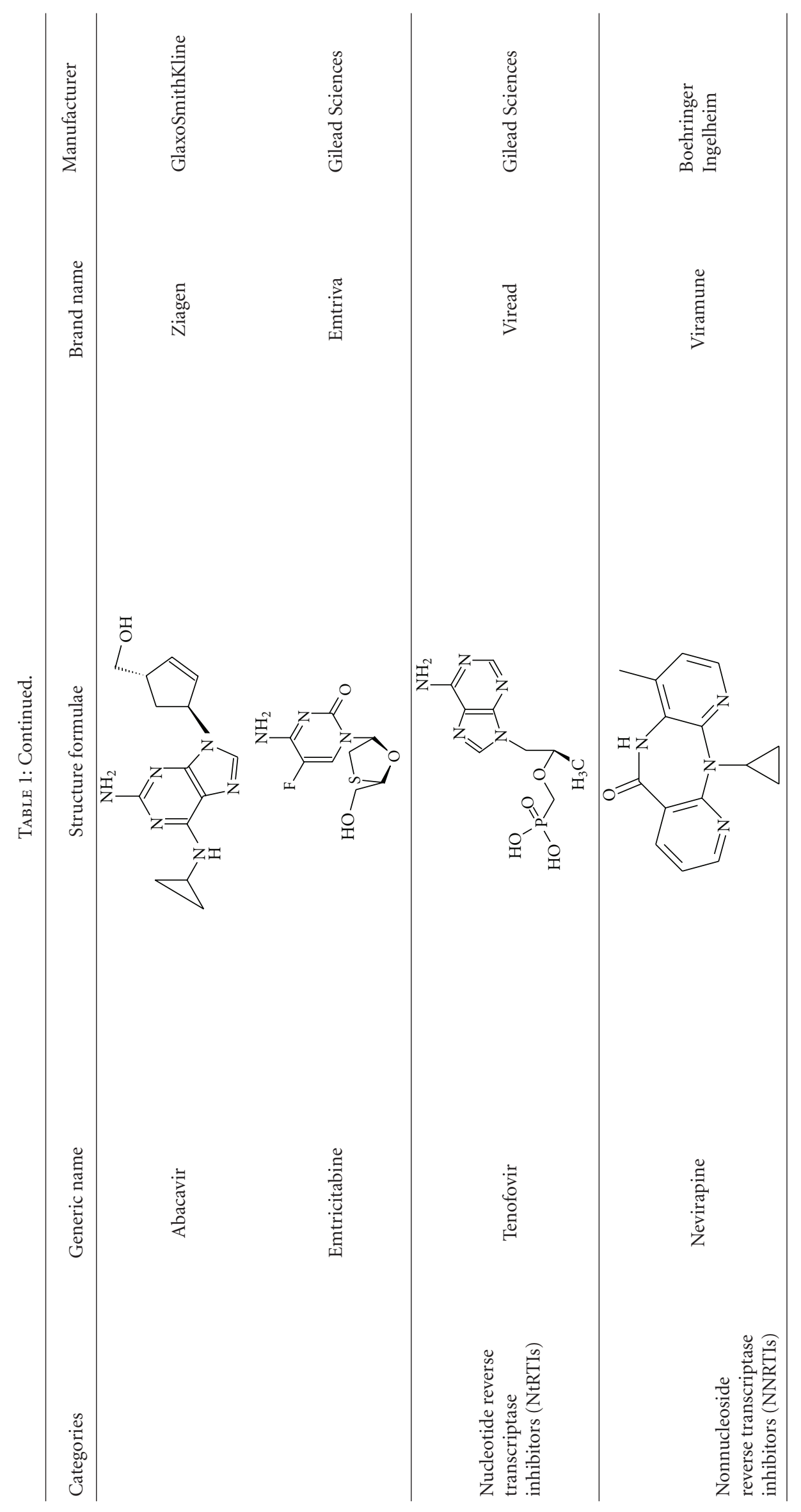




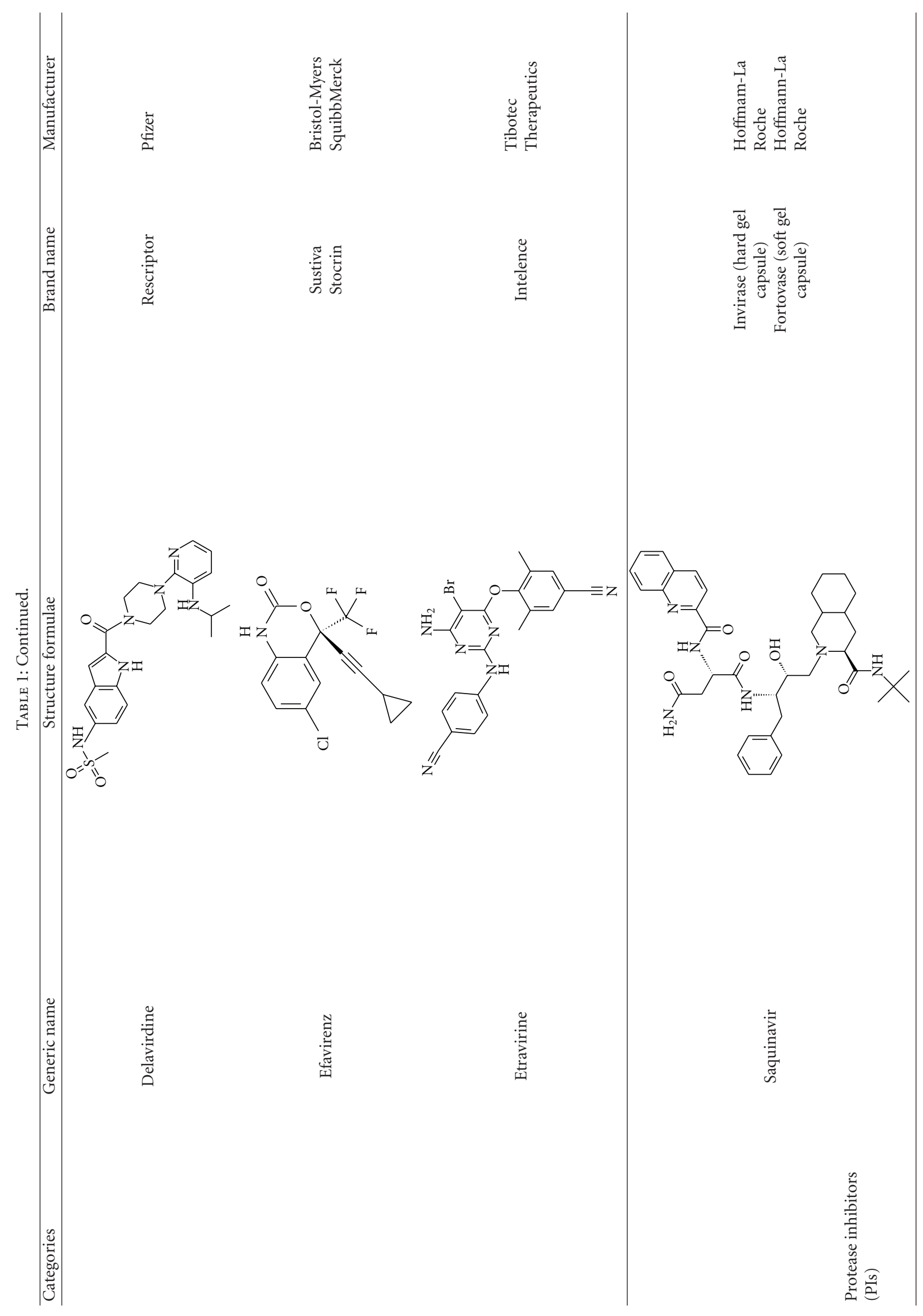




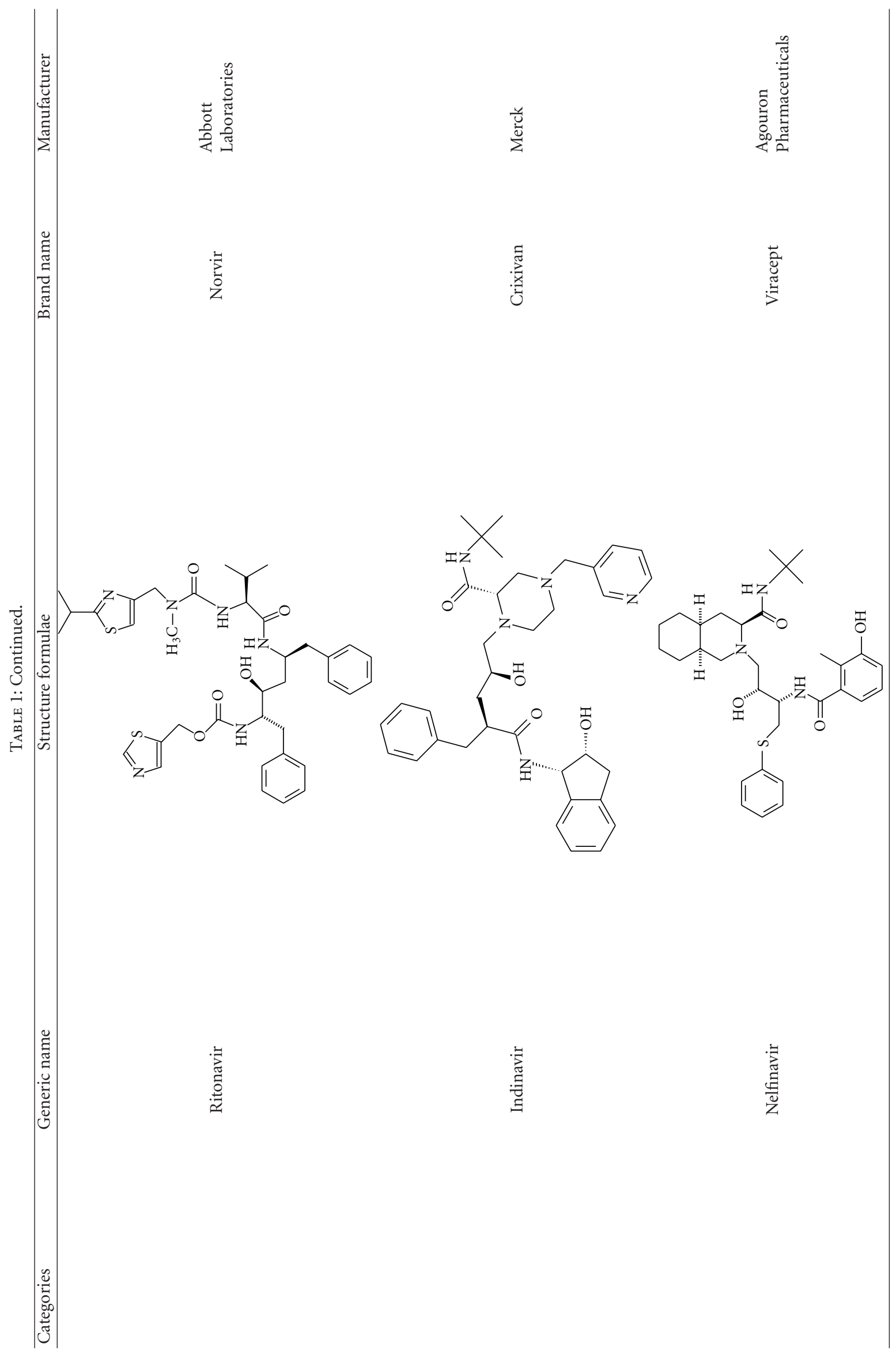




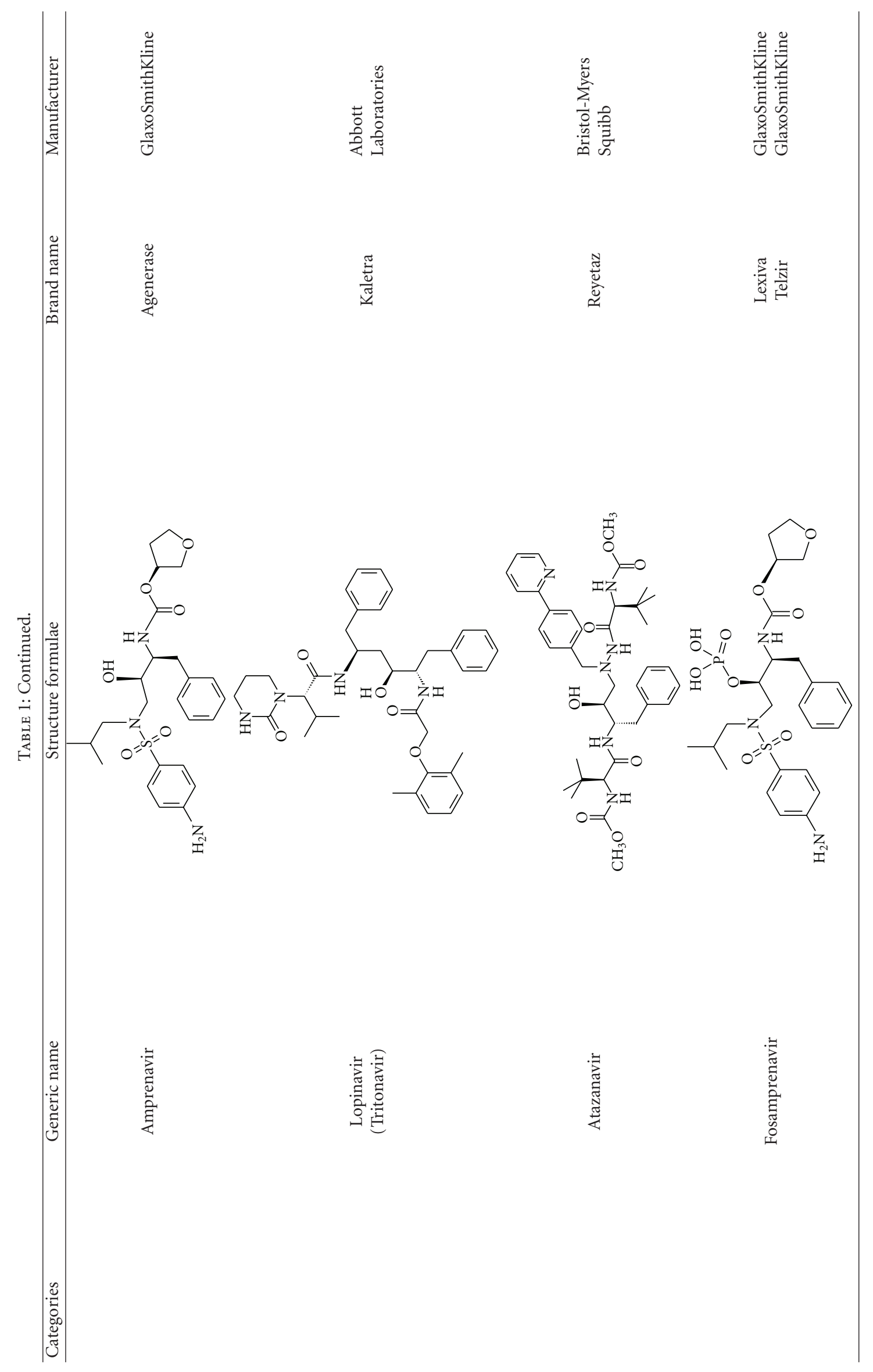




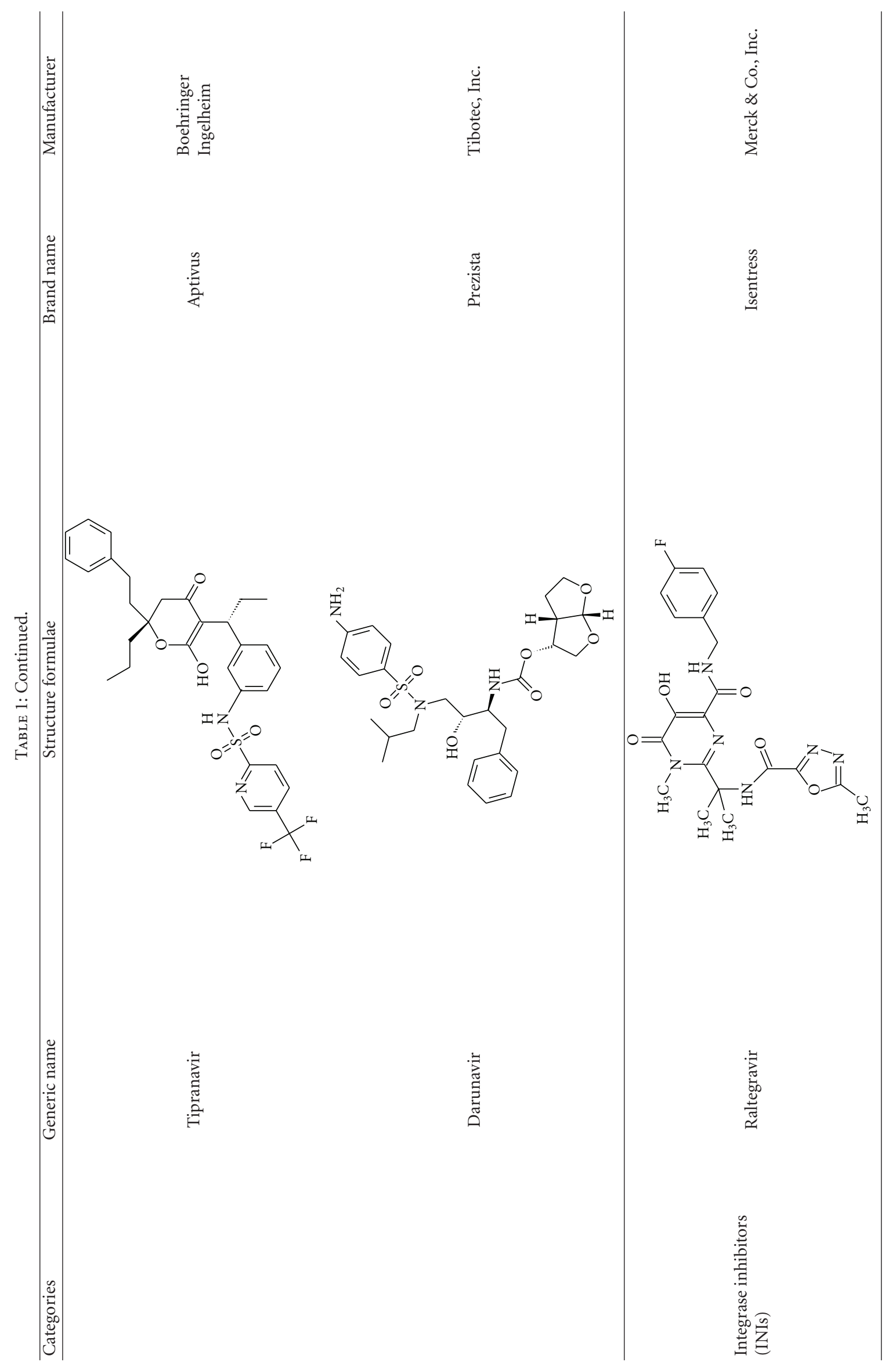




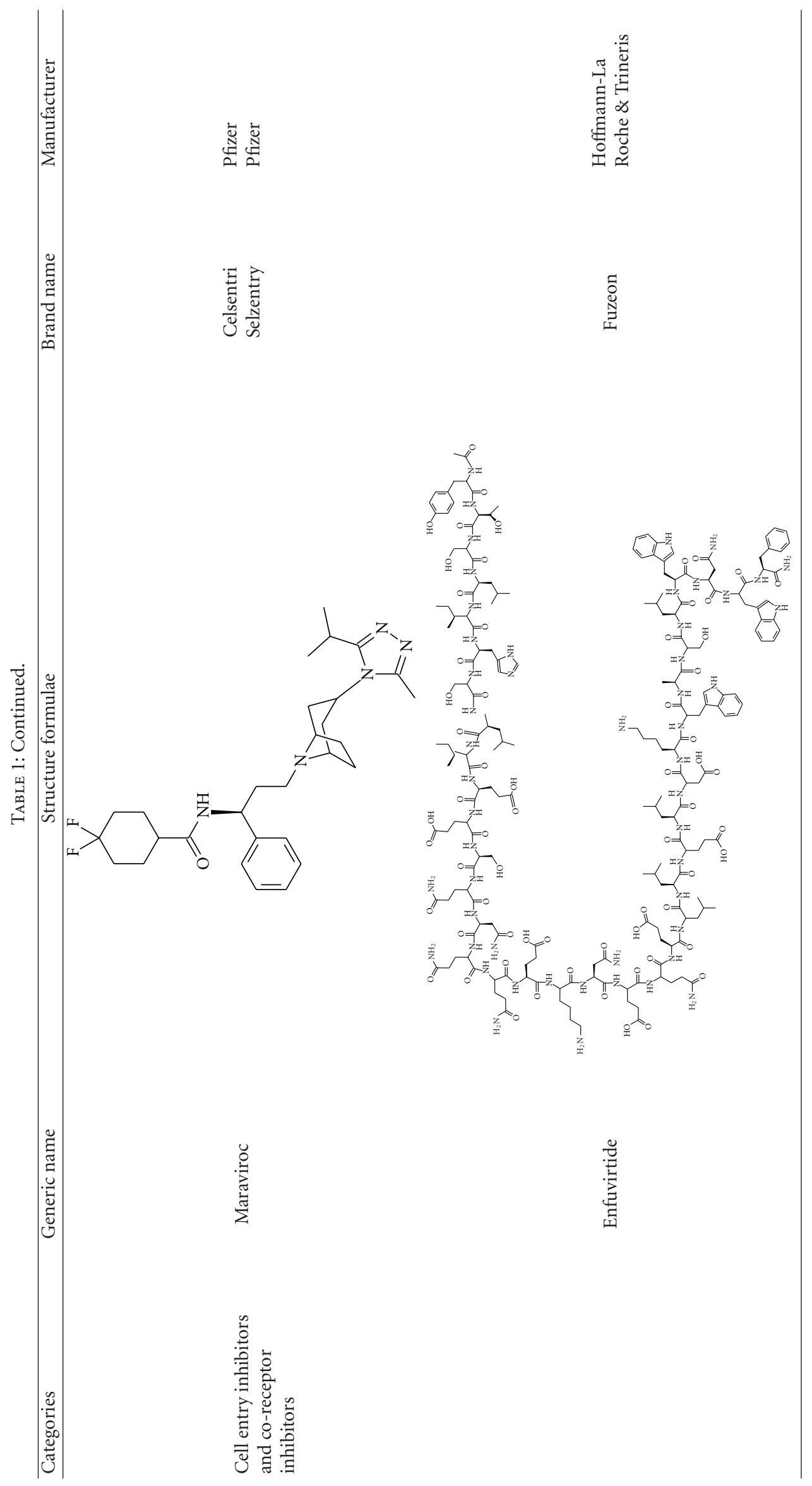


effective against HIV-2, as the pocket of the HIV-2 reverse transcriptase has a different structure, which confers intrinsic resistance to the NNRTI class. EFV is metabolized in the liver and possesses both inhibitory and including effects on the 3A4 isoform of the cytochrome P450 system. This means EFV may interact with other drugs metabolized in the liver, requiring either increased or decreased dosages $[18,19]$. Electrochemical techniques also help for the identification of the redox mechanism of drug compounds and provide important information about DNA-drug interaction [20]. There is only one electroanalytical method for the determination of EFV in dosage forms. Dogan-Topal et al. [20] investigated the voltammetric behavior of EFV at a PGE and presented DNA biosensor. The aim of this study was to establish the experimental conditions such as EFV concentration, its interaction time dsDNA, dsDNA concentration, and the effect of the ionic strength. These results showed that this DNA biosensor could be used for the sensitive, rapid, simple, and cost-effective detection and determination of EFV-dsDNA interaction. The linearity was between 2 and 24 ppm of EFV concentration on guanine signal decreasing curve. This work also aimed to develop a new, selective, simple voltammetric method for the direct determination of EFV in raw material and pharmaceutics without any time-consuming extraction, evaporation, and separation steps prior to drug assay. Also DPV method was used at bare and dsDNA modified disposable PGE. EFV showed an irreversible oxidation behavior at all $\mathrm{pH}$ values, and AdsDPV method was developed for determination of EFV. Under these conditions, the current showed a linear dependence with concentration in the range between 0.018 and $2.56 \mathrm{ppm}$.

2.2. Abacavir. ABA, $\{((1 \mathrm{~S}, \mathrm{cis})-4$-[2-amino-6-(cyclopropylamino)-9H-purin-9-yl]cyclopent-2-enyl)methanol\}, is an NRTI with antiretroviral activity against HIV. It is a carbocyclic synthetic nucleoside analog. ABA is rapidly absorbed following oral administration with a bioavailability of about $80 \%$. It is about $50 \%$ bound to plasma proteins. $\mathrm{ABA}$ is metabolized into the pharmacological inactive $5^{\prime}$-glucuronide and the $5^{\prime}$-carboxylate.

ABA has been studied and determined using anodic voltammetry by Uslu and Özkan [21]. The goal of this work was the development of new voltammetric methods (DPV and SWV) for the direct determination of ABA in pharmaceutical dosage forms, raw materials, spiked human serum, and urine samples. These two voltammetric techniques for the determination of ABA in Britton-Robinson buffer at $\mathrm{pH} 2.0$, which allows quantitation over the $8 \times 10^{-7}$ to $2 \times 10^{-4} \mathrm{M}$ range in supporting electrolyte for both methods were proposed. The linear response was obtained in BrittonRobinson buffer in the ranges of $1 \times 10^{-5}$ to $1 \times 10^{-4} \mathrm{M}$ for spiked urine sample at $\mathrm{pH} 2.0$ and $2 \times 10^{-5}$ to $2 \times 10^{-4} \mathrm{M}$ for spiked serum samples at $\mathrm{pH} 3.0$ for both techniques.

$\mathrm{ABA}$ is electrochemically reduced at the dropping mercury electrode in a four-electron process, similar to structurally related adenine, and adenosine triphosphate [22]. Procedures of analyses of tablets containing ABA were established and validated, based on peak currents obtained by LSV, DPV, or SWV with an HMDE as indicator electrode. The procedure proved to be more sensitive and more reliable than based on oxidation on a glassy carbon electrode.

2.3. Fosamprenavir. FOS, $\{(2 \mathrm{R}, 3 \mathrm{~S})-1-[\mathrm{N}-(2-\mathrm{methylpropyl})$ (4-aminobenzene) sulfonamido]-3-(\{[(3S)-oxolan-3-yloxy] carbonyl $\}$ amino) 4-phenyl butan-2-yloxy] carbonyl $\}$ amino)-4-phenylbutan-2-yl] oxy \} phosphonic acid is a prodrug of antiretroviral protease inhibitor amprenavir. Amprenavir is metabolized in the liver by CYP3A4 enzyme system. It is an inhibitor of HIV-1 protease. Amprenavir binds to the active site of $\mathrm{HIV}-1$ protease resulting in the formation of immature noninfectious viral particles $[18,23,24]$. The two major metabolites result from oxidation of the tetrahydrofuran and aniline moieties. Several analytical methods have been published for the determination of amprenavir with other HIV protease inhibitors in biological fluids, based on HPLC with MS detection, with UV detection, and with fluorescence detection. Also there is only one published literature related to electroanalytical studies of amprenavir. In this study, the anodic oxidation of fosamprenavir was investigated using $\mathrm{CV}$ and LSV at boron-doped diamond and glasy carbon electrodes. In $\mathrm{CV}$, depending on $\mathrm{pH}$ values, FOS showed one sharp irreversible oxidation peak or wave depending on the electrode. The aim of this study was to determine FOS levels in pharmaceutical formulations and biological samples by means of electrochemical methods. DPV and SWV techniques were $0,1 \mathrm{M} \mathrm{H}_{2} \mathrm{SO}_{4}$ and phosphate buffer at $\mathrm{pH} 2.0$ which allow quantitation over a $4 \times 10^{-6}$ to $8 \times$ $10^{-5} \mathrm{M}$ range using boron-doped diamond and $1 \times 10^{-5}$ to $1 \times 10^{-4} \mathrm{M}$ range using glassy carbon electrodes, respectively, in supporting electrolyte [25].

2.4. Didanosine. 2'-3'-Dideoxyinosine (DDI), 9-[(2R, 5S)5-(hydroxymethyl) oxolan-2-yl]-6,9-dihydro-3H-purin-6one, is a dideoxy analogue of the purine nucleoside inosine, which shows high antiretroviral activity against HIV, the agent of AIDS [26]. DDI was approved as a drug in 1991 by the FDA for the treatment of adults and children with advanced HIV infection, who are intolerant or resistant to azidothymidine therapy or whose health has been deteriorated by azidothymidine use [27].

Electroanalytical determination of DDI is possible; however up to now, there is only one published paper. In this study, cobalt (II) phthalocyanine and iron (II) phthalocyanine complexes have been used as an electrocatalysts for the oxidation of DDI [28]. The detection limits were calculated to be $8.80 \times 10^{-7} \mathrm{M}$ for CoPc-CPE with a linear concentration range between $2.0 \times 10^{-6}--7.0 \times$ $10^{-4} \mathrm{M}$, whereas for the FePc-CPE the LOD is $3.50 \times 10^{-7} \mathrm{M}$ with a linear concentration range between $1.0 \times 10^{-6}$ and $8.0 \times 10^{-4} \mathrm{M}$ in $\mathrm{pH} 7.4$ phosphate buffer solution. Also the main advantage of the proposed method over the other known methods described for DDI is a possibility of its determination directly, without prior separation, with high precision, rapidity, stability, and low consumption of sample and buffer. 
2.5. Indinavir. IND, [1(1S,2R),5(S)]-2,3,5-trideoxy-N-(2,3-dihydro-2-hydroxy-1H-inden-1-yl)-5-[2-[[(1,1-dimethyl ethyl)-amino] carbonyl]-4-(3-pyridinylmethyl)-1-piperazinyl]2-phenylmethyl)-D-erythro-pentonamide sulfat is an inhibitor of the HIV protease. IND has a low protein binding ranging from 60 to $70 \%$ in species and is extensively metabolized in all species by the cytochrome P450 system. It has been determined by spectrophotometric, capillary electrophoretic, liquid chromatographic methods; however, all the reported methods are laborious, time-consuming and require highly sophisticated instrumentation. Only one paper reported anodic voltammetry using glassy carbon electrode. In this study, pH 6.0 Britton-Robinson buffer solution was selected for analytical medium in which IND exhibited diffusion controlled oxidative peak at $+0.89 \mathrm{~V}$. Also the peak current varied linearly with drug concentration in the range between $2.8 \times 10^{-7}$ and $5.0 \times 10^{-5} \mathrm{M}$. The proposed DPV and SWV techniques have been applied to the determination of IND in pharmaceutical dosage forms with good recoveries [29]. Besides, there is only one electroanalytical study about the determination and reduction mechanism of IND in bulk form, pharmaceutical dosage forms, and biological fluids. In this study, IND exhibited irreversible cathodic waves over the $\mathrm{pH}$ range of 2.0-12.00 in different supporting electrolytes. The current-concentration plot was rectilinear over the range from $8.0 \times 10^{-7}$ to $8.0 \times 10^{-6} \mathrm{M}$ for DPV and $8.0 \times 10^{-7}-1.0 \times 10^{-5} \mathrm{M}$ for SWV in Britton-Robinson buffer at $\mathrm{pH} 10.00$. The wave was characterized as being irreversible and diffusion controlled also. The proposed methods were fully validated and successfully applied to the determination of IND in capsules and spiked human serum samples with good recoveries [30]. Ignaszak et al. [31] developed a novel therapeutic biosensor for the determination of IND. An amperometric drug metabolism biosensor consisting of CYP3A4 encapsulated in a didodecyldimethyl ammonium bromide vesicular system on a platinum disk electrode was fabricated. CV, SWV, and pulse voltammetric responses of the bioelectrode showed quasireversible electrochemistry of the $\mathrm{Fe}^{3+} / \mathrm{Fe}^{2+}$ redox species of the heme thiolate CYP3A4 enzyme under aerobic and anaerobic conditions. The new biosensor exhibited excellent response to IND with a detection limit and response time of $6.158 \times 10^{-2} \mathrm{mgL}^{-1}$ and $40 \mathrm{~s}$, respectively. Also detection limit was well below the plasma concentration of IND ( $8 \mathrm{~h}$ after intake) which ranges from 0.13 to $8.6 \mathrm{mgL}^{-1}$ [31]. Fizzano et al. [32] developed an HPLC method with electrochemical detection for the quantification of IND in cell culture. For the electrochemical detector, the working parameters were $+400 \mathrm{mV}$ for the first electrode and $+750 \mathrm{mV}$ for the second; these setting were found to provide optimal detection conditions. The signals generated by the second electrode were used for the quantitation. Also the proposed HPLC assay was utilized to directly evaluate the capability of p-glycoprotein expressing multidrug resistant cells in meading the transport and efflux of protease inhibitor IND, a basic compound in AIDS care.

2.6. Lamivudine. LAM, 4 -amino-1-[(2R,5S)-2-(hydroxymethyl)-1,3-oxathiolan-5-yl]-1,2-dihydro pyrimidin-2-one, is a synthetic nucleoside analogue with activity against HIV-1 and hepatitis B virus. It is an NRTI structurally related to cytosine with activity against retroviruses including HIV. It is used usually in combination with other antiretroviral drugs. Following oral administration, LAM is rapidly absorbed and peak plasma concentrations are achieved in about 1 hour. Binding to plasma protein is reported to be less than $36 \%$ $[18,33]$.

Nowadays, there are two published literatures related to electrochemical study of LAM in pharmaceutical dosage forms. One of them was studied by Dogan et al. [34]. The aim of this study was to determine LAM levels in serum and pharmaceutical formulations, by means of electrochemical methods using HMDE. On this electrode, LAM undergoes irreversible reduction at the peak potential near Ep $-1.26 \mathrm{~V}$. Reduction LAM signals were measured DPV and SWV techniques. DPV and SWV techniques for the determination of LAM in asetate buffer at $\mathrm{pH} 4.5$, which allows quantitation over the $4.0 \times 10^{-6}--1.0 \times 10^{-4} \mathrm{M}$ range for both methods, were proposed. The linear response was obtained in acetate buffer in the ranges of $2.0 \times 10^{-6}$ to $2.0 \times 10^{-4} \mathrm{M}$ for spiked serum samples at $\mathrm{pH} 4.5$ for both techniques.

Another study was developed by Jain et al. [35]. The electrochemical reduction and adsorption of LAM were studied in a phosphate buffer at pH 3.4 at an HMDE. The reduction was irreversible and exhibited diffusion-controlled adsorption. The responses were evaluated with respect to preconcentration time, $\mathrm{pH}$ effect, accumulation potential, accumulation time, and scan rate. The calibration plot of the peak current versus the concentration was found to be linear over the range of $500 \mathrm{ng} / \mathrm{mL}$ to $10 \mu \mathrm{g} / \mathrm{mL}$ for LAM in the SWV method. Also the number of electrons transferred in the reduction process was calculated and the probable reduction mechanism was proposed.

2.7. Zidovudine (Azidothymidine). ZDV, 3'-azido-3'-deoxythymidine, is the cornerstone drug for treatment of patients with HIV-1. ZDV is derived from thymidine where the hydroxyl group at carbon 3 of the sugar moiety is replaced by the azide. The azido group is responsible not only for the in vivo antiviral activity but also for the electrochemical reduction signal of ZDV on a mercury electrode. The electrochemical properties of ZDV were investigated using $\mathrm{CV}, \mathrm{DPV}$, and chronocoulometry [36]. These methods were used to determine the reduction pathway of ZDV and the number of protons and electrons involved in the reduction process. Experiments using a narrow range of moderate scan rates indicate that the electrochemical reduction of ZDV proceeds via a four-electron, two-proton mechanism to a reduced species that undergoes a fast chemical reaction to give a species that precipitates on the electrode surface. The diffusion coefficient for ZDV was calculated to be $4.90 \times$ $10^{-6} \mathrm{~cm}^{2} \mathrm{~s}^{-1}$ using the irreversible CV equation and an $\mathrm{n}$ value of four electrons. The electrochemical investigation was studied by SWV, LSV, and elimination voltammetry with linear scan using HMDE. This paper explores the possibility of determining ZDV in the presence of native (dsDNA) or denatured calf thymus DNA (ssDNA), and/or same synthetic oligodeoxynucleotides. The detection limit of ZDV in the absence and in the presence of ssDNA $(10 \mu \mathrm{g} / \mathrm{mL})$ is 1 and 
$250 \mathrm{nM}$, respectively. It was found that the signal of ZDV is not substantially affected by the presence of DNA. While ZDV provides an irreversible reduction peak at a potential near $-1.1 \mathrm{~V}$, the DNA gives the reduction peak due to adenine and cytosine residues at a potential of ca. $-1.4 \mathrm{~V}$ [37].

Other similar experiment was developed by Vacek et al. [38]. The aim of this study was to determine ZDV levels in natural samples (urine, serum, whole blood, and cell cultures) without their mineralization and/or purification, by means of electrochemical methods using HMDE. Reduction ZDV signals were measured by CV, DPV, SWV, and constant current chronopotentiometric stripping analysis. In phosphate buffer at $\mathrm{pH} 8.0$, the SWV yielded the best ZDV signal with the detection limit of $1 \mathrm{nM}$. For monitoring the influence of these compounds, $\mathrm{ZDV}$ reduction was performed in the presence of $10 \mu \mathrm{g} / \mathrm{mL}$ calf thymus ssDNA and/or $100 \mu \mathrm{g} / \mathrm{mL}$ bovine serum albumin. In these cases, the detection limit increased to $0.25 \mu \mathrm{M}$. The work showed that SWV is a suitable electrochemical method for the determination of ZDV in various biological samples, such as cell cultures and body liquids of HIV-positive patients. Also the SWV method can be recommended as a useful tool for pharmacological and metabolic studies of ZDV.

New simple and direct electroanalytical method was developed for the determination of ZDV in commercial pharmaceutical preparations by Peckova et al. [39]. It is based on DPV at p-AgSAE or m-AgSAE. Achieved LOQs are in the $10^{-7} \mathrm{M}$ concentration range for both amalgam electrodes. This is more than one order of magnitude higher than using HMDE, nevertheless, still attractive for determination of ZDV in pharmaceutical preparations and in biological matrices, especially after a preconcentration step using solid phase or liquid-liquid extraction.

Another DPV method has been described for the quantitative determination of ZDV by Leandro et al. [40]. In this study, the reduction of ZDV at an HMDE was at $-0.96 \mathrm{~V}$ at pH 8.0 phosphate buffer. Under these optimized conditions, the ZDV peak current varied linearly with its concentration from 0.25 to $1.25 \mathrm{mg} / \mathrm{L}$. Detection and determination limits of 0.0025 and $0.025 \mathrm{mg} / \mathrm{L}$, respectively, and recovery of $99.88 \%$ with an RSD of $0.95 \%$ were obtained.

Mahmoud and Luong developed highly sensitive screening assay based on electrochemical impedance spectroscopy [41]. The assay format was based on the immobilization of the thiol terminated ferrocene $(\mathrm{Fc})$-pepstatin conjugate on a single-walled carbon nanotube/gold nanoparticle modified gold electrode. This study has demonstrated for the first time the use of nanomaterials in impedance spectroscopy for detecting lopinavir, ritonavir, saquinavir, indinavir, and fosamprenavir at picomolar levels. Thiolated single-walled carbon nanotubes together with gold nanoparticles and a ferrocene conjugate serve as sensitive enhancer tools in this assay format. On the basis of its applicability for evaluation of low-molecular weight compounds, this technique is a definite asset for the expedited development of effective HIV1 protease inhibitors. This strategy might be extended for the sensing of other interfacial interactions such as enzymeDNA, antibody-antigen, and cell receptor.

\section{Simultaneous Electroanalytical Determination of Analyzed Drugs}

Besides the analytical methods for single components, some of the simultaneous determinations are also included in this paper. Lamivudine, didanosine, and saquinavir were simultaneously determined by capillary zone electrophoresis [42]. In this study, the anti-HIV drug mixture of lamivudine, didanosine, and saquinavir was separated and quantitated in human serum with capillary zone electrophoresis. The effects of various factors, such as run buffer type, buffer concentration, and $\mathrm{pH}$ on the separation were investigated. All analytes were separated within $10 \mathrm{~min}$ with a voltage of $+20 \mathrm{kV}$ and a current around $30 \mu \mathrm{A}$ in the $\mathrm{pH} 2.5$ phosphate buffer. The method was validated over the range of $0.4-$ $37.8 \mu \mathrm{g} / \mathrm{mL}$ for lamivudine, $1.4-34.0 \mu \mathrm{g} / \mathrm{mL}$ for didanosine, and $0.5-24.4 \mu \mathrm{g} / \mathrm{mL}$ for saquinavir. Baseline separation of lamivudine, didanosine, and saquinavir was achieved with retention times of $4.4,10.8$, and $6.9 \mathrm{~min}$, respectively. The internal standard diltiazem gave a migration time of $5.6 \mathrm{~min}$.

MEKC was used for determination of stavudine, didanosine, saquinavir (mixture A) and stavudine, didanosine, efavirenz (mixture B) in human serum samples [43]. The optimized resolution of both mixture was achieved with a run buffer containing $18 \mathrm{mM}$ sodium dodecylsulfate in $15 \mathrm{mM}$ phosphate and borate buffer ( $\mathrm{pH} 9.0)$. All analytes were separated within $15 \mathrm{~min}$ with a voltage of $+15 \mathrm{kV}$ and a current around $30 \mu \mathrm{A}$. The methods were validated over the range of $0.7-35.3 \mu \mathrm{g} / \mathrm{mL}$ for stavudine, $0.8-18.5 \mu \mathrm{g} / \mathrm{mL}$ for didanosine, $0.5-12.2 \mu \mathrm{g} / \mathrm{mL}$ for saquinavir in mixture A and $0.7-35.3 \mu \mathrm{g} / \mathrm{mL}$ for stavudine, $0.8-18.5 \mu \mathrm{g} / \mathrm{mL}$ for didanosine, and $0.6-31.9 \mu \mathrm{g} / \mathrm{mL}$ for efavirenz in mixture B.

Another MEKC method was developed by Fan and Stewart [44]. In this study, the anti-HIV drug mixtures containing zidovudine/didanosine/nevirapine (mixture A) and zidovudine/didanosine/ritonavir (mixture B) were quantitated in human serum samples. All analytes were separated within 14 min with a voltage of $+15 \mathrm{kV}$ and a current around $30 \mu \mathrm{A}$. The methods were validated over the range of $0.5-$ $25.0 \mu \mathrm{g} / \mathrm{mL}$ for zidovudine, $0.8-18.5 \mu \mathrm{g} / \mathrm{mL}$ for didanosine, $0.5-22.8 \mu \mathrm{g} / \mathrm{mL}$ for nevirapine in mixture $\mathrm{A}$ and the range of $0.5-25.0 \mu \mathrm{g} / \mathrm{mL}$ for zidovudine, $0.8-18.5 \mu \mathrm{g} / \mathrm{mL}$ for didanosine, and $1.2-28.8 \mu \mathrm{g} / \mathrm{mL}$ for ritonavir in mixture $\mathrm{B}$.

\section{Validation of the Electroanalytical Methods}

Validation of a method is the planned and documented procedure to establish its performance characteristics. Typical parameters that characterize each electroanalytical method include selectivity, specificity, range, linearity, accuracy (recovery), LOD, LOQ, precision, robustness, and ruggedness [45-52]. They define what the method can do under optimized conditions of matrix solution, instrumental settings, active ingredient isolation, and other experimental features.

The electroanalytical procedures presented in this paper have been validated in terms of basic parameters, that is, linearity, LOD, LOQ, precision, and recovery. Validation parameters of the electroanalytical methods used for 


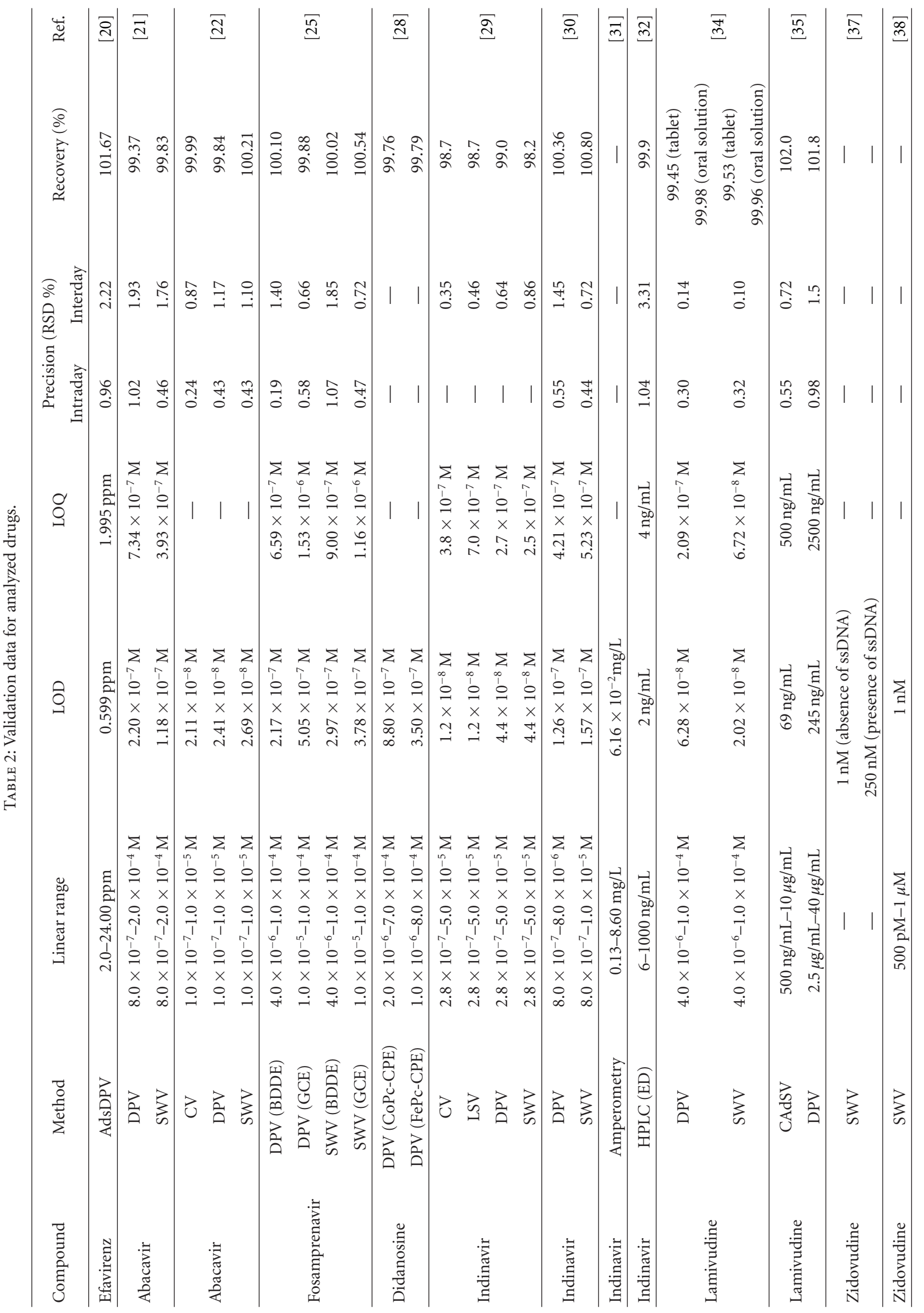




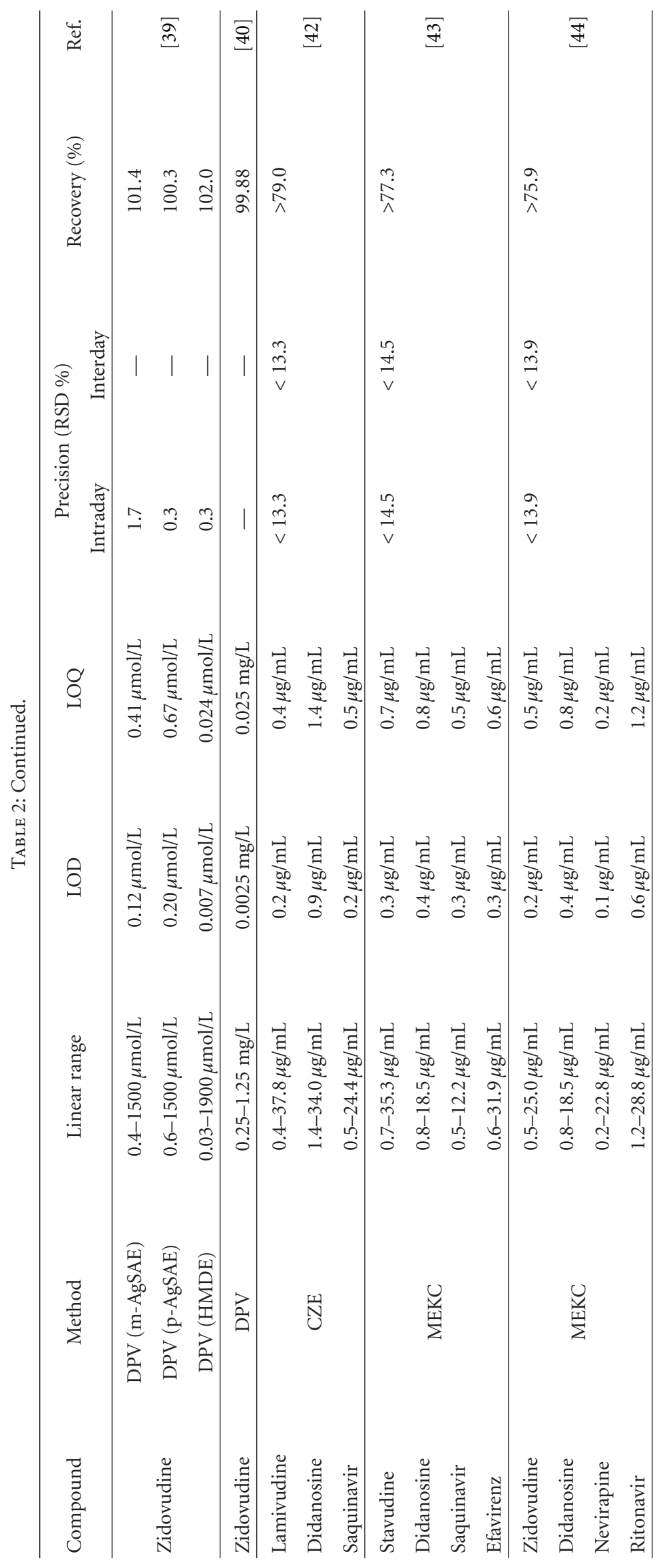


the determination of efavirenz, abacavir, fosamprenavir, didanosine, indinavir, lamivudine, zidovudine, saquinavir, stavudine, nevirapine, and ritonavir are presented in Table 2. Comparing validation parameters of already researched techniques, it can be concluded which one of them is more sensitive (low LOD and LOQ values), accurate (precision and recovery) and allows marking in a broad linearity scope.

\section{Conclusions}

This paper presents electroanalytical methods applied for the determination of anti-HIV drugs between 1990 and 2010. A great number of studies on zidovudine, indinavir, and lamivudine can be noted, whereas for efavirenz, abacavir, fosamprenavir, and didanosine are only a few. Among all of the published methods, DPV and SWV techniques are the most popular techniques which are used both for the analysis of pharmaceutical dosage forms and biological samples. Other techniques, that is, CV, LSV, and amperometry are not so popular. They are used only for understanding redox mechanism. Another technique used for mixture components separation is zone electrophoresis, in which after separation, the individual components can be analyzed in the buffer solution using a spectrophotometric or electrochemical dedector. MEKC is a mode of capillary electrophoresis that is capable of separating uncharged compounds. It is viewed as a chromatographic technique in which migrating charged micelles act as a pseudostationary phase. MEKC offers analyte partitioning between micelles formed by a surfactant in the run buffer, such that mixtures of charged and uncharged anti-HIV drugs can be satisfactorily separated. Up to date a lot of new modified electrodes and biosensors were developed for determination of antiHIV drugs. The ultimate goal is to obtain results with more and more precision and accuracy and at increasingly lower concentration levels of the substances being determined.

\section{Abbreviations}

$\begin{array}{ll}\text { DPV: } & \text { Differential pulse voltammetry } \\ \text { SWV: } & \text { Square wave voltammetry } \\ \text { CV: } & \text { Cyclic voltammetry } \\ \text { LSV: } & \text { Lineer sweep voltammetry } \\ \text { CoPc-CPE: } & \text { Cobalt (II) phthalocyanine carbon paste } \\ & \text { ele- } \\ & \text { ctrode } \\ \text { FePc-CPE: } & \text { Iron (II) phthalocyanine carbon paste ele- } \\ & \text { ctrode } \\ \text { HPLC: } & \text { High performance liquid chromatography } \\ \text { HMDE: } & \text { Hanging mercury drop electrode } \\ \text { dsDNA: } & \text { Double-stranded DNA } \\ \text { ssDNA: } & \text { Single-stranded DNA } \\ \text { EFV: } & \text { Efavirenz } \\ \text { FDA: } & \text { Food and Drug Administration } \\ \text { HIV-1: } & \text { Human immunodeficiency virus type } 1 \\ \text { HIV-2: } & \text { Human immunodeficiency virus type } 2 \\ \text { AdsDPV: } & \text { Differential pulse adsorptive stripping } \\ & \text { voltammetry } \\ \text { ABA: } & \text { Abacavir }\end{array}$

FOS: $\quad$ Fosamprenavir

MS: $\quad$ Mass

UV: Ultraviole

DDI: Didanosine

IND: Indinavir

AIDS: $\quad$ Acquired immune deficiency syndrome

LAM: Lamivudine

ZDV: $\quad$ Zidovudine

p-AgSAE: Silver solid amalgam electrode with polished surface

m-AgSAE: Surface modified by mercury meniscus

RSD: $\quad$ Relative standard deviation

LOD: Detection limit

LOQ: Quantitation limit

MEKC: Micellar electrokinetic chromatography

NRTIs: Nucleoside reverse transcriptase inhibitors

NtRTIs: Nucleotide reverse transcriptase inhibitors

NNRTIs: Nonnucleoside reverse transcriptase inhibitors

PIs: $\quad$ Protease inhibitors

INIs: Integrase inhibitors

PGE: $\quad$ Pencil graphite electrode

CYP3A4: Cytochrome P450-3A4

GCE: Glassy carbon electrode

BDDE: Boron-doped diamond electrode

ED: $\quad$ Electrochemical detection

CAdSV: Cathodic adsorptive stripping voltammetry

CZE: Capillary zone electrophoresis.

\section{References}

[1] E. De Clercq, "Anti-HIV drugs: 25 compounds approved within 25 years after the discovery of HIV," International Journal of Antimicrobial Agents, vol. 33, no. 4, pp. 307-320, 2009.

[2] J. E. Gallant, "Initial therapy of HIV infection," Journal of Clinical Virology, vol. 25, no. 3, pp. 317-333, 2002.

[3] B. G. Kalzung, S. B. Masters, and A. J. Trevor, Eds., Basic \& Clinical Pharmacology, McGraw Hill Medical, New York, NY, USA, 11th edition, 2010.

[4] M. R. Sadaie, R. Mayner, and J. Doniger, "A novel approach to develop anti-HIV drugs: adapting non-nucleoside anticancer chemotherapeutics," Antiviral Research, vol. 61, no. 1, pp. 1-18, 2004.

[5] D. J. Back, S. H. Khoo, S. E. Gibbons, H. Reynolds, J. F. Tjia, and C. Merry, "Therapeutic drug monitoring of anti-HIV drugs," International Congress Series, vol. 1220, pp. 145-160, 2001.

[6] X. Tan, C. K. Chu, and F. D. Boudinot, "Development and optimization of anti-HIV nucleoside analogs and prodrugs: a review of their cellular pharmacology, structure-activity relationships and pharmacokinetics," Advanced Drug Delivery Reviews, vol. 39, no. 1-3, pp. 117-151, 1999.

[7] P. T. Kissinger and W. R. Heineman, Eds., Laboratory Techniques in Electroanalytical Chemistry, Marcel Dekker, New York, NY, USA, 2nd edition, 1996.

[8] J. Wang, Analytical Electrochemistry, Wiley-VCH, New York, NY, USA, 2000.

[9] M. R. Smyth and J. G. Vos, Analytical Voltammetry, vol. XXVII, Elsevier Science, Amsterdam, The Netherlands, 1992.

[10] J. P. Hart, Ed., Electroanalysis of Biologically Important Compounds, Ellis Harwood, New York, NY, USA, 1990. 
[11] R. Kellner, J. M. Mermet, M. Otto, M. Valcarcel, and H. M. Widmer, Eds., Analytical Chemistry: A Modern Approach to Analytical Science, Wiley-VCH, Weinheim, Germany, 2nd edition, 2004.

[12] J. Wang, Ed., Electroanalytical Techniques in Clinical Chemistry and Laboratory Medicine, Wiley-VCH, New York, NY, USA, 1988.

[13] D. K. Gosser Jr., Ed., Cyclic Voltammetry: Simulation and Analysis of Reaction Mechanism, Wiley-VCH, New York, NY, USA, 1993.

[14] G. Christian, Ed., Analytical Chemistry, John Wiley \& Sons, Hoboken, NJ, USA, 6th edition, 2004.

[15] B. Uslu and S. A. Ozkan, "Solid electrodes in electroanalytical chemistry: present applications and prospects for high throughput screening of drug compounds," Combinatorial Chemistry and High Throughput Screening, vol. 10, no. 7, pp. 495-513, 2007.

[16] S. A. Özkan, B. Uslu, and H. Y. Aboul-Enein, "Analysis of pharmaceuticals and biological fluids using modern electroanalytical techniques," Critical Reviews in Analytical Chemistry, vol. 33, no. 3, pp. 155-181, 2003.

[17] B. Uslu and S. A. Ozkan, "Electroanalytical application of carbon based electrodes to the pharmaceuticals," Analytical Letters, vol. 40, no. 5, pp. 817-853, 2007.

[18] S. C. Sweetman, Ed., Martindale the Complete Drug Reference, Pharmaceutical Press, 35th edition, 2007.

[19] K. D. Sanbar, Ed., Physicans' Desk Reference (PDR), Thomson PDR, Montvale, NJ, USA, 61st edition, 2007.

[20] B. Dogan-Topal, B. Uslu, and S. A. Ozkan, "Voltammetric studies on the HIV-1 inhibitory drug Efavirenz: the interaction between dsDNA and drug using electrochemical DNA biosensor and adsorptive stripping voltammetric determination on disposable pencil graphite electrode," Biosensors and Bioelectronics, vol. 24, no. 8, pp. 2358-2364, 2009.

[21] B. Uslu and S. A. Özkan, "Anodic voltammetry of abacavir and its determination in pharmaceuticals and biological fluids," Electrochimica Acta, vol. 49, no. 25, pp. 4321-4329, 2004.

[22] B. Dogan, B. Uslu, S. A. Ozkan, and P. Zuman, "Electrochemical determination of HIV drug abacavir based on its reduction,” Analytical Chemistry, vol. 80, no. 1, pp. 209-216, 2008.

[23] J. Weiss, J. Rose, C. H. Storch et al., "Modulation of human BCRP (ABCG2) activity by anti-HIV drugs," Journal of Antimicrobial Chemotherapy, vol. 59, no. 2, pp. 238-245, 2007.

[24] Lexiva ${ }^{\circledR}$ US prescribing information, GlaxoSmithKline, 2008.

[25] M. Gumustas and S. A. Ozkan, "Electrochemical evaluation and determination of antiretroviral drug fosamprenavir using boron-doped diamond and glassy carbon electrodes," Analytical and Bioanalytical Chemistry, vol. 397, no. 1, pp. 189-203, 2010.

[26] M. Nasr, C. Litterst, and J. McGowan, "Computer-assisted structure-activity correlations of dideoxynucleoside analogs as potential anti-HIV drugs," Antiviral Research, vol. 14, no. 3, pp. 125-148, 1990.

[27] G. D. Morse, M. J. Shelton, and A. M. O’Donnell, "Comparative pharmacokinetics of antiviral nucleoside analogues," Clinical Pharmacokinetics, vol. 24, no. 2, pp. 101-123, 1993.

[28] K. I. Ozoemena, R. I. Stefan-von Stoden, and T. Nyokong, "Metallophthalocyanina based carbon paste electrodes for the determination of 2'-3'-dideoxyinosine," Electroanalysis, vol. 21, pp. 1651-1654, 2009.

[29] N. Erk, "Voltammetric behavior of indinavir and determination in pharmaceutical dosage forms," Analytical Letters, vol. 37, no. 1, pp. 47-63, 2004.
[30] B. Dogan, D. Canbaz, S. A. Ozkan, and B. Uslu, "Electrochemical methods for determination of the protease inhibitor indinavir sulfate in pharmaceuticals and human serum," Pharmazie, vol. 61, no. 5, pp. 409-413, 2006.

[31] A. Ignaszak, N. Hendricks, T. Waryo et al., "Novel therapeutic biosensor for indinavir - a protease inhibitor antiretroviral drug," Journal of Pharmaceutical and Biomedical Analysis, vol. 49, no. 2, pp. 498-501, 2009.

[32] M. R. Fizzano, L. Valvo, M. L. Dupuis, V. Mennella, and M. Cianfriglia, "LC determination of Indinavir in biological matrices with electrochemical detection," Journal of Pharmaceutical and Biomedical Analysis, vol. 22, no. 2, pp. 307-314, 2000.

[33] $\mathrm{PDR}^{\circledR}$, Electronic Library, Thomson Medical Economics, Mantuale, NJ, USA, 2003.

[34] B. Dogan, B. Uslu, S. Suzen, and S. A. Ozkan, "Electrochemical evaluation of nucleoside analogue lamivudine in pharmaceutical dosage forms and human serum," Electroanalysis, vol. 17, no. 20, pp. 1886-1894, 2005.

[35] R. Jain, N. Jadon, and K. Radhapyari, "Cathodic adsorptive stripping voltammetric studies on lamivudine: an antiretroviral drug," Journal of Colloid and Interface Science, vol. 313, no. 1, pp. 254-260, 2007.

[36] G. C. Barone, H. B. Halsall, and W. R. Heineman, "Electrochemistry of azidothymidine," Analytica Chimica Acta, vol. 248, no. 2, pp. 399-407, 1991.

[37] L. Trnková, R. Kizek, and J. Vacek, "Square wave and elimination voltammetric analysis of azidothymidine in the presence of oligonucleotides and chromosomal DNA," Bioelectrochemistry, vol. 63, no. 1-2, pp. 31-36, 2004.

[38] J. Vacek, Z. Andrysík, L. Trnková, and R. Kizek, "Determination of azidothymidine - an antiproliferative and virostatic drug by square-wave voltammetry," Electroanalysis, vol. 16, no. 3, pp. 224-230, 2004.

[39] K. Pecková, T. Navrátil, B. Yosypchuk, J. C. Moreira, K. C. Leandro, and J. Bareka Jiri, "Voltammetric determination of azidothymidine using silver solid amalgam electrodes," Electroanalysis, vol. 21, no. 15, pp. 1750-1757, 2009.

[40] K. C. Leandro, J. C. Moreira, and P. A. M. Farias, "Determination of zidovudine in pharmaceuticals by differential pulse voltammetry," Analytical Letters, vol. 43, no. 12, pp. 1951-1957, 2010.

[41] K. A. Mahmoud and J. H. T. Luong, "Impedance method for detecting HIV-1 protease and screening for its inhibitors using ferrocene-peptide conjugate/Au nanoparticle/single-walled carbon nanotube modified electrode," Analytical Chemistry, vol. 80, no. 18, pp. 7056-7062, 2008.

[42] B. Fan and J. T. Stewart, "Determination of lamivudine/didanosine/saquinavir in human serum using capillary zone electrophoresis," Journal of Liquid Chromatography and Related Technologies, vol. 25, no. 2, pp. 241-249, 2002.

[43] B. Fan and J. T. Stewart, "Determination of stavudine/didanosine/saquinavir and stavudine/didanosine/efavirenz in human serum by micellar electrokinetic chromatography (MEKC)," Journal of Liquid Chromatography and Related Technologies, vol. 25, no. 6, pp. 937-947, 2002.

[44] B. Fan and J. T. Stewart, "Determinations of zidovudine/ didanosine/nevirapine and zidovudine/didanosine/ritonavir in human serum by micellar electrokinetic chromatography," Journal of Pharmaceutical and Biomedical Analysis, vol. 30, no. 4, pp. 955-960, 2002.

[45] ICH Harmonised Tripartite Guideline, ICH Steering Committee, November 1996, İnc. November 2005. 
[46] B. Uslu and S. A. Ozkan, "Solid electrodes in electroanalytical chemistry: present applications and prospects for high throughput screening of drug compounds," Combinatorial Chemistry and High Throughput Screening, vol. 10, no. 7, pp. 495-513, 2007.

[47] B. Bozal, B. Doĝan-Topal, B. Uslu, S. A. Özkan, and H. Y. Aboul-Enein, "Quantitative analysis of irbesartan in pharmaceuticals and human biological fluids by voltammetry," Analytical Letters, vol. 42, no. 14, pp. 2322-2338, 2009.

[48] B. Dogan-Topal, B. Bozal, B. Tolga Demircigil, B. Uslu, and S. A. Ozkan, "Electroanalytical studies and simultaneous determination of amlodipine besylate and atorvastatine calcium in binary mixtures using first derivative of the ratio-voltammetric methods," Electroanalysis, vol. 21, no. 22, pp. 2427-2439, 2009.

[49] B. Uslu and D. Canbaz, "Anodic voltammetry of zolmitriptan at boron-doped diamond electrode and its analytical applications," Pharmazie, vol. 65, no. 4, pp. 245-250, 2010.

[50] D. Kul, M. Gumustas, B. Uslu, and S. A. Ozkan, "Electroanalytical characteristics of antipsychotic drug ziprasidone and its determination in pharmaceuticals and serum samples on solid electrodes," Talanta, vol. 82, pp. 286-295, 2010.

[51] Y. Altun, B. Uslu, and S. A. Ozkan, "Electroanalytical characteristics of lercanidipine and its voltammetric determination in pharmaceuticals and human serum on boron-doped diamond electrode," Analytical Letters, vol. 43, no. 12, pp. 1958-1975, 2010.

[52] B. Bozal and B. Uslu, "Applications of carbon based electrodes for voltammetric determination of lornoxicam in pharmaceutical dosage form and human serum," Combinatorial Chemistry and High Throughput Screening, vol. 13, no. 7, pp. 599-609, 2010. 


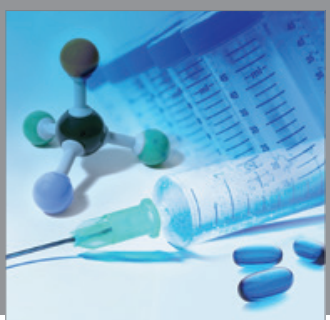

International Journal of

Medicinal Chemistry

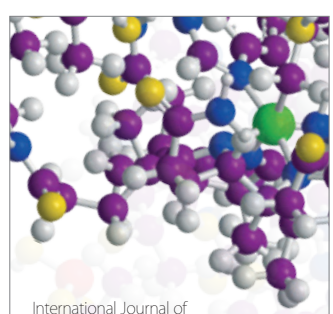

Carbohydrate Chemistry

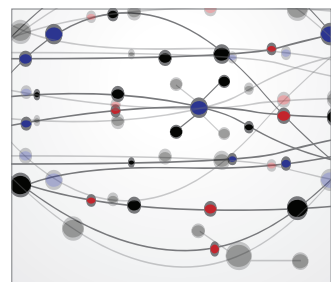

The Scientific World Journal
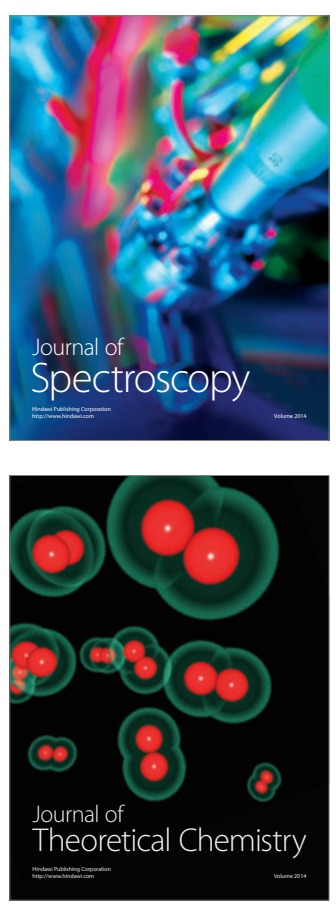
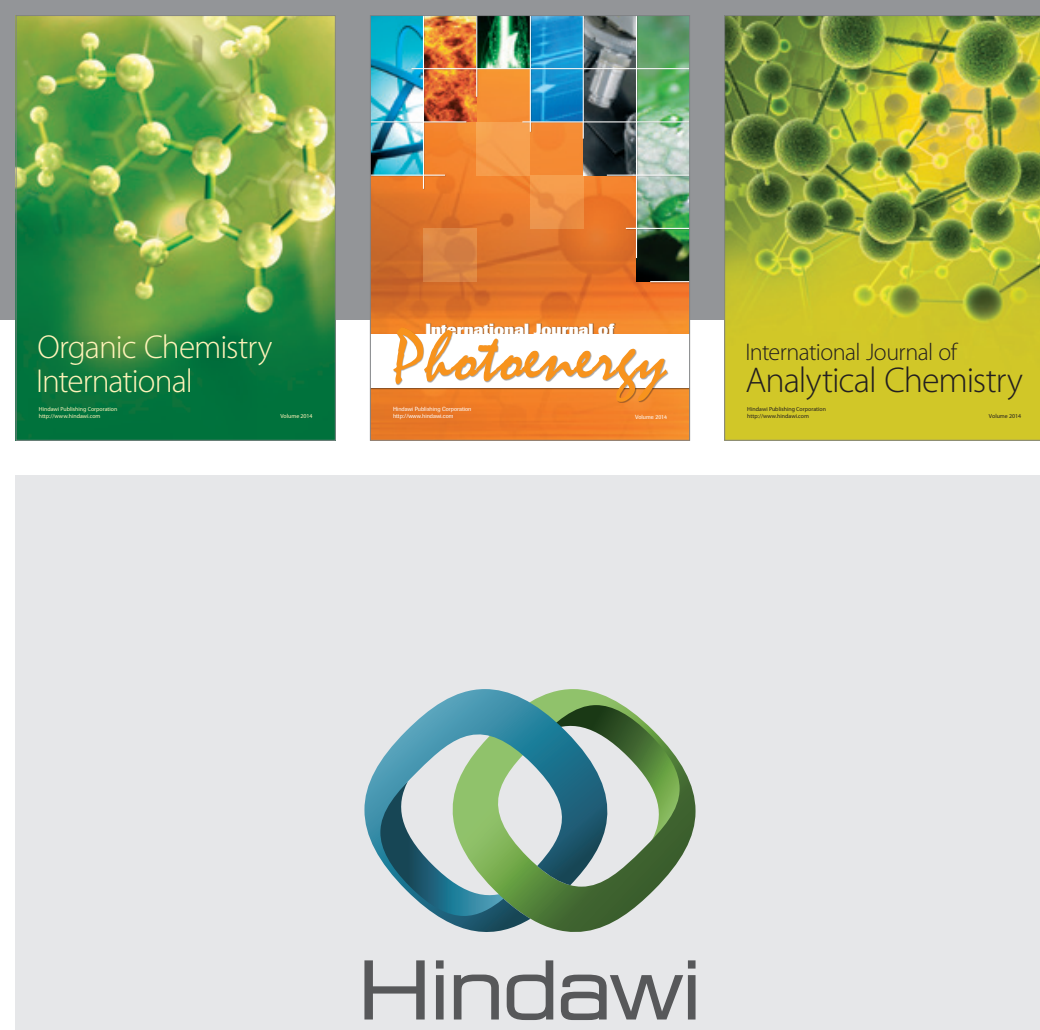

Submit your manuscripts at

http://www.hindawi.com
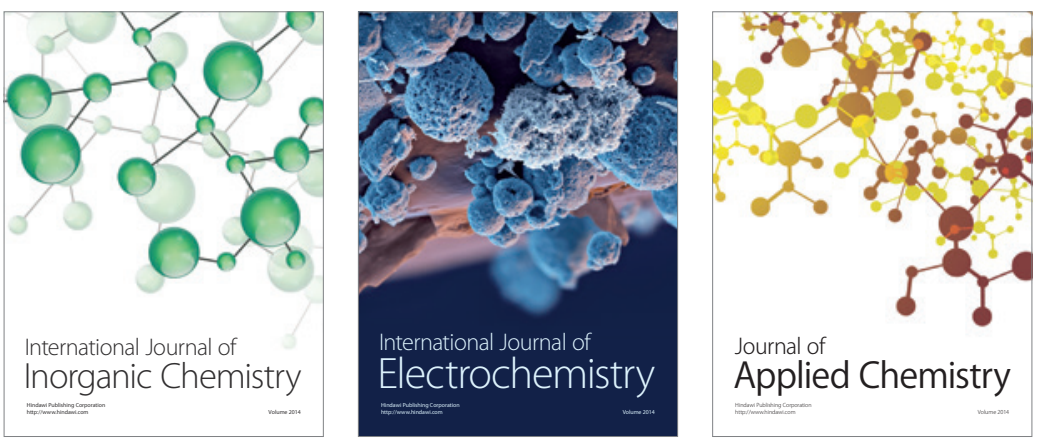

Journal of

Applied Chemistry
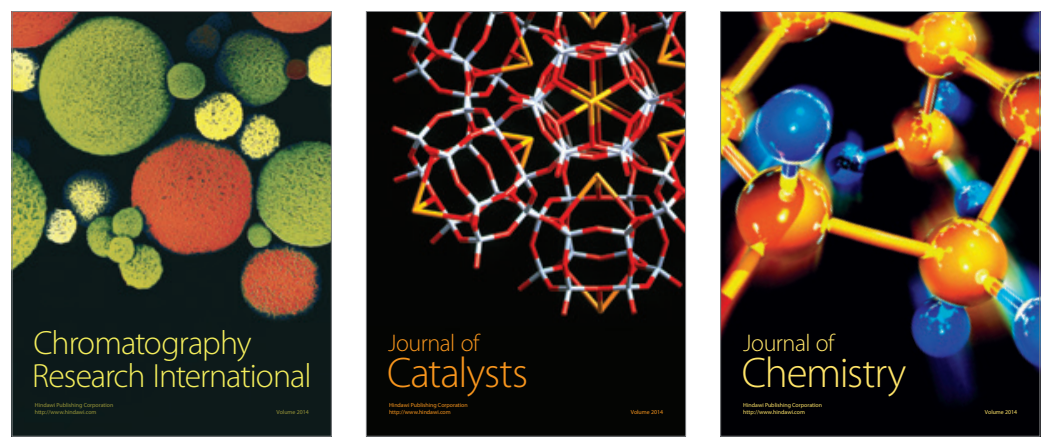
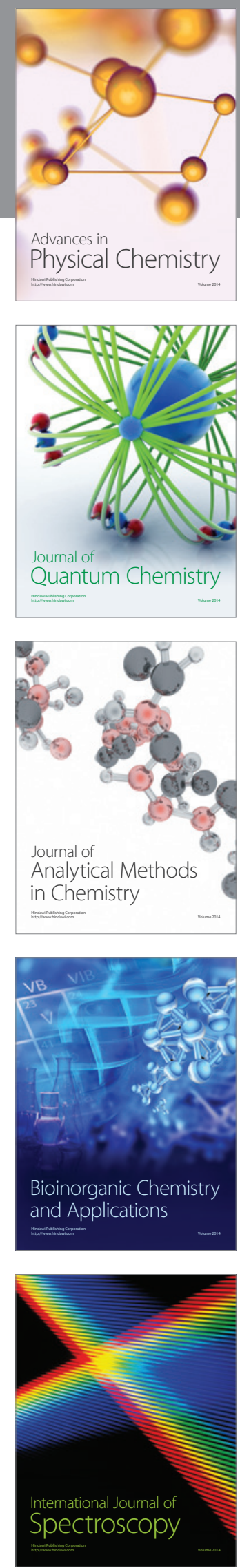